\title{
Highly sensitive amperometric sensor for morphine detection based on electrochemically exfoliated graphene oxide. Application in screening tests of urine samples.
}

\author{
Giulio Maccaferri, ${ }^{\mathrm{a}, \mathrm{b}}$ Fabio Terzi, ${ }^{\mathrm{a}}$ Zhenyuan Xia, ${ }^{\mathrm{c}}$ Fabio Vulcano, ${ }^{\mathrm{a}}$ Andrea Liscio, ${ }^{\mathrm{d}}$ Vincenzo
} Palermo, ${ }^{\text {b,c }}$ Chiara Zanardi*,a,b

\footnotetext{
${ }^{\mathrm{a} D e p a r t m e n t ~ o f ~ C h e m i c a l ~ a n d ~ G e o l o g i c a l ~ S c i e n c e s, ~ U n i v e r s i t a ̀ ~ d i ~ M o d e n a ~ e ~ R e g g i o ~ E m i l i a, ~ V i a ~ G . ~}$ Campi 103, 41125 Modena, Italia.

${ }^{\mathrm{b}}$ Istituto di Sintesi organica e Fotoreattività (ISOF), Consiglio Nazionale della Ricerca (CNR), via Gobetti 101 - 40129 Bologna, Italia.

${ }^{c}$ Department of Industrial and Materials Science, Chelmers University of Technology, SE-412 96 Gothenburg, Sweden

${ }^{\mathrm{d}}$ Istituto per la microelettronica e microsistemi (IMM), Consiglio Nazionale della Ricerca (CNR), sezione di Roma, via del Fosso del Cavaliere 100 - 00133 Roma, Italia.

* corresponding author: chiara.zanardi@unimore.it
}

\begin{abstract}
Graphene oxide modified screen-printed electrodes have been tested as amperometric sensors for morphine determination. The results demonstrate that the arising of electrocatalytic processes ascribable to the graphene coating, combined with the use of a suitable cleaning procedure, allow the sensor to achieve higher sensitivity $\left(2.61 \mathrm{nA} \mathrm{ppb}^{-1}\right)$ and lower limit of detection (2.5 ppb) with respect to those reported in the literature for similar devices.

Due to very low detection limit found, the device is suitable to detect the presence of morphine in urine samples after a very simple and rapid pre-treatment of the matrix, allowing the removal of interfering species affecting the voltammetric responses. Tests performed in synthetic urine samples demonstrate that the presence of the electrocatalytic coating is mandatory in resolving the peak due to morphine oxidation in respect to uric acid. The sensor proposed is, thus, suitable to detect this drug even at concentration values below the cut-off levels defined by European and American regulations. These results allow us to propose the sensor for screening tests in portable devices, to be applied in systematic controls of drug abuses, e.g. in drivers and in men at work.
\end{abstract}




\section{Keywords:}

morphine; graphene; electrocatalysis; drug detection; screening tests; urine samples

\section{Introduction}

Morphine is a highly effective drug for the treatment of severe pains, because it acts directly on the central nervous system, where it mimics the effects of the endorphins, i.e. endogenous neuropeptides possessing powerful analgesic and exciting activity.

It is extracted for opium poppy straw. The yearly production worldwide is estimated to more than five hundred tons [1]. Only ten percent of morphine produced is directly used in pain therapies, with an increase of more than four times over the last twenty years. The most part of morphine, in fact, is used as the starting compound for the synthesis of other opioids, such as hydromorphone, oxymorphone and heroin, whose analgesic effect and addiction are so strong to be considered as drugs of abuse [1-3]. On the other hand, morphine itself is also considered an illicit drug, exhibiting potentially serious side effects, such as slow respiratory rate and low blood pressure, and constitutes an indicator of abuse of other opioids, being one of their metabolites [4].

Due to all these effects, this analyte requires to be strictly monitored in many environmental and biological samples. Low detection and quantification limits are necessary to define the path followed by morphine after assumption, to assess its presence in the environment, as well as to give answer to problems arising in different frames of forensic sciences.

As a consequence of the importance of morphine detection for human health and for identification of opiates abuse, many quantitative analytical methods have been developed. They mainly consist of gas chromatography with mass spectrometric detection [5-7] or of liquid chromatographic techniques $[8,9]$. These analyses not only require suitable laboratory equipment, sample pretreatments and qualified personnel, but are also time consuming. Although these techniques are mandatory for the quantification of morphine in the case of legal controversies [10,11], they are not practical for a first screening of the population in systematic controls. For instance, the check of the possible occurrence of drug abuses, e.g. by drivers directly on the road or by workers at job, may require fast routine controls. Such a control strategy can be only adopted by using portable sensing systems equipped by disposable sensor probes. By following this approach, the sensor system may not be required to actually quantify drugs, but, rather, to identify subjects under potential altered state to select them for a further evaluation in a clinical laboratory. It should lead to an as low as possible number of false negatives, i.e. of responses that are erroneously estimated to be within the noise confidence interval, whereas a limited number of false positives does not constitute a serious 
drawback.

Several progresses along this direction have been recently made by the development of amperometric sensors, which base the detection on the occurrence of electrochemical oxidation of morphine. Morphine oxidation occurs by one electron charge transfer to the phenoxide ion at the 3position, followed by dimerization of the free radical to pseudomorphine [4,12-14]. Two additional anodic responses are observed at higher potentials, consisting in the further oxidation of pseudomorphine and in the two-electron oxidation of the tertiary amine group. While morphine is oxidised at relatively low potentials, most of the other opiates, not possessing phenol groups in the molecule, are only oxidisable at higher potentials. This peculiarity has been exploited for the selective determination of morphine in samples also containing different opiates, namely codeine, heroine and noscapine [15-18].

Despite the number of amperometric sensors developed so far for the analysis of morphine (see Table 1), none of them was tested for morphine detection in biological fluids at the cut-off limits. In any case, the presence of a suitable coating modifying the electrode surface may induce electrocatalytic properties that on the one hand anticipates the signal of the analyte and, on the other hand, increases the sensitivity of detection [19,20]. However, adsorption phenomena, generally occurring as a consequence of the oxidation of a phenol [21,22], constitute eventual major obstacle for the actual efficiency of amperometric sensors for morphine detection.

In this paper, screen-printed electrode (SPE) modified by a graphene oxide coating has been tested as an amperometric sensor for morphine. Based on our previous studies concerning the performance of this kind of nanosized material [23], electrochemically exfoliated graphene oxide (EGO) has been used as the electrode coating. At variance with different graphene oxide materials, it possesses appropriate density of oxidised functional groups on the surface to be conductive without the need of any reduction pre-treatment. We could prove here that the EGO coating induces anticipation of the electrochemical response due to morphine oxidation with respect to bare SPE, leading to higher sensor sensitivity and lower detection limit. The analytical performance of this modified electrode was defined by tests in standard solutions only containing this species in order to be compared with that of different amperometric devices reported by the literature.

Due to particularly good results found, this sensor was tested for the possible detection of morphine in urine samples at concentration values close to the cut-off limits defined for the screening tests in urine samples, ranging from $300 \mathrm{ppb}$ in several European countries [10] to $2000 \mathrm{ppb}$ in USA [11]. Experiments performed in synthetic urine samples allowed us to put in light, once more, the advantage in the use of EGO modified electrodes for the detection of morphine in the presence of uric acid, constituting an electroactive component of this matrix. Finally, screening tests of 
morphine in the real matrix were found possible after the development of a very rapid and automatable sample pre-treatment.

\section{Materials and methods}

\subsection{Instruments and electrodes}

All electrochemical measurements were performed using a computerized Autolab PGSTAT 30 (Ecochemie, Utrecht, The Netherlands). SPEs were acquired from DropSens (Llanera, Asturias, Spain) and consisted of a $4 \mathrm{~mm}$ diameter graphite working electrode, a graphite auxiliary electrode and an Ag pseudo-reference electrode. The surface of the working electrode was prepared by dropping $6 \mu \mathrm{L}$ of $0.5 \mathrm{gL}^{-1} \mathrm{EGO}$ dispersion in isopropylic alcohol (IPA), obtained from graphite according to the method previously reported [23,37]. The solvent was allowed to evaporate at room temperature. The amount of EGO finally present on each electrode was $0.020 \mathrm{mg} \cdot \mathrm{cm}^{-2}$. As previously defined [23], the amount of material deposited is enough to achieve complete coverage of the electrode surface, but not to induce significant variation of the electroactive surface area.

After deposition, the working electrode was submitted to five subsequent cyclic voltammetric (CV) sweeps between 0.00 and $+0.60 \mathrm{~V}$, at $0.05 \mathrm{Vs}^{-1}$ potential scan rate, in $0.1 \mathrm{M}$ phosphate buffer solution (PBS). The device is now considered ready for morphine detection.

\subsection{Morphine detection in buffer solutions}

All reagents, morphine included, were of analytical grade and supplied by Sigma-Aldrich. Deionised water $(18 \mathrm{M} \Omega \cdot \mathrm{cm})$ was always used. Standard solutions of morphine were prepared in PBS, at $\mathrm{pH}$ 7.0. All solutions used for electrochemical tests with SPEs, even when not specified, also contain $0.1 \mathrm{M} \mathrm{KCl}$ to fix the potential of the reference electrode.

Preliminary tests on morphine oxidation at bare and at modified electrode surfaces were carried out by $\mathrm{CV}$ in a $0.16 \mathrm{mM}$ morphine solution, performing five subsequent potential scans between 0.00 and $+0.60 \mathrm{~V}$, at $0.05 \mathrm{Vs}^{-1}$ scan rate.

The construction of calibration plots for morphine at low concentrations was performed both at bare and at EGO modified SPEs, by differential pulse voltammetry (DPV) technique, by scanning the electrode potential between +0.10 and $+0.50 \mathrm{~V}$, adopting the following waveform parameters: 50 $\mathrm{mV}$ pulse potential, $6 \mathrm{mV}$ step potential, 0.1 modulation time and $0.4 \mathrm{~s}$ time elapsed between two subsequent pulses. 
Between two following tests in morphine solutions, the electrode was treated by five CV scans in $0.1 \mathrm{M} \mathrm{KOH}$, in order to remove products of morphine oxidation strongly adsorbed on the surface. Repeatability of the analytical response was tested by performing three following voltammetric tests in 30, 60 and $220 \mathrm{ppb}$ morphine solutions with the same EGO/SPE. The value of RSD\% finally reported is the mean of the RSD values calculated from voltammetric responses recorded in each of these solutions.

As to reproducibility, it was defined by recording voltammetric traces in these same solutions with three EGO/SPEs obtained in similar conditions. The value of RSD\% finally reported is the mean of the RSD values obtained. As further indicator of sensor reproducibility we also compared the slope values calculated from calibration plots obtained with three similar EGO/SPEs.

\subsection{Morphine detection in synthetic urine}

Analyses of morphine in synthetic urine samples were performed in order to test the possible presence of electroactive species interfering with morphine oxidation response. For this reason, a chemical composition as close as possible to the real matrix was prepared. In agreement with DIN EN 1616:1999 standard procedure, synthetic urine samples where obtained with $25.0 \mathrm{gL}^{-1}$ urea, 9.0 $\mathrm{gL}^{-1} \mathrm{KCl}, 3.0 \mathrm{gL}^{-1} \mathrm{NH}_{4} \mathrm{Cl}, 3.0 \mathrm{gL}^{-1} \mathrm{Na}_{2} \mathrm{SO}_{4} \cdot 10 \mathrm{H}_{2} \mathrm{O}, 2.5 \mathrm{gL}^{-1} \mathrm{KH}_{2} \mathrm{PO}_{4}, 2.5 \mathrm{gL}^{-1} \mathrm{~K}_{2} \mathrm{HPO}_{4}, 2.0 \mathrm{gL}^{-1}$ creatinine, and $0.35 \mathrm{gL}^{-1}$ uric acid. The final $\mathrm{pH}$ of this solution was $6.6( \pm 0.1)$.

Stock solutions of synthetic urine, either containing or not morphine, were diluted five times with 0.1 M PBS before DPV analyses. Electrochemical tests were performed with waveform parameters equal to those previously reported.

\subsection{Morphine detection in real samples}

Real samples of urine have been obtained from healthy voluntaries. They were added with an amount of morphine suitable to achieve a concentration even lower than the cut-off limit actually defined, i.e. $200 \mathrm{ppb}$. In order to minimize interference effects of different species present in urine (discussed in Results and Discussion section) on the electrochemical signal, $10 \mu \mathrm{L}$ of $12 \mathrm{M} \mathrm{HCl}$ were added to $400 \mu \mathrm{L}$ of the sample. The suspension was then filtered through a $0.2 \mu \mathrm{m}$ syringe nylon filter (Whatman) and the filtered solution was diluted with 0.1 M PBS ( $\mathrm{pH}=7.0)$ to a final dilution factor of five, leading to a sample containing a $40 \mathrm{ppb}$ final concentration of morphine. Also in these cases the values of the parameters defining the DPV waveform were the same as those for standard solutions in pure PBS. 


\section{Results and Discussion}

\subsection{Voltammetric detection of morphine in PBS}

The electrochemical behaviour of EGO/SPE has been already tested in the presence of a reversible redox species, namely $\left[\mathrm{Fe}(\mathrm{CN})_{6}\right]^{2-}[23]$. $\mathrm{CV}$ responses evidence that $\Delta \mathrm{E}$ is similar to that measured at bare SPE, indicating a lower resistance of the EGO film with respect to coatings obtained by deposition of graphene oxide produced by Hummer method [38], constituting the synthetic approach more frequently adopted. Furthermore, voltammetric responses indicate that the presence of the nanostructured coating does not modify the total electroactive surface with respect to the underlying electrode surface.

The evaluation of the electrocatalytic behaviour of EGO coatings with respect to morphine oxidation was performed by comparing CV traces collected at bare and at modified SPEs, in PBS only containing the analyte. As observed in Figure 1, the EGO coating induces a significant anticipation of the oxidation peak potential of morphine, from $+0.44 \mathrm{~V}$ to $+0.35 \mathrm{~V}$, with respect to the bare electrode. Concurrently, the value of the peak current increases. Both these factors indicate the activation of an electrocatalytic process induced by the presence of EGO coating on the electrode surface [20,39-41].

The advantages described for EGO coatings have been exploited in quantitative analyses performed by more sensitive DPV technique. DPV is acknowledged to enhance the signal-to-noise ratio and, consequently, to reduce the limit of detection (LOD) with respect to CV; on its turn, it also lowers the concentration limit for false negatives [42,43], improving the effectiveness of detection with respect to this important issue.

Aiming at comparing the performance of EGO/SPE with that of similar electrode systems reported in the literature (see Table 1), calibration with a single electrode system has been performed, calculated on the basis of voltammetric responses collected in solutions at very low concentration of morphine (see Figure 2). In order to evidence the possible presence of memory effects, subsequent measurements were performed by randomizing the order under which solutions at different analyte concentration were analysed. We could observe that quite a good linear correlation between the peak intensity and the concentration of morphine was achieved only after the development of a cleaning procedure suitable to significantly reduce the effects of surface fouling. As a matter of fact, passivation of the electrode surface is not surprising at all, because it resembles what has been already evidenced for electrochemical processes involving phenol derivatives [21,22]. Best results in terms of repeatability ( $\mathrm{RSD}=7.2 \%$ ) were obtained by performing five subsequent $\mathrm{CV}$ cycles in a strong alkaline solution $(0.1 \mathrm{M} \mathrm{KOH})$ between two subsequent DPV analyses. This procedure 
allows the use of the device for many electrochemical analyses, e.g., in this case, to perform all the measurements required to calculate the calibration plot.

On the other hand, it should be recalled that SPEs are generally used as disposable sensor systems, so that the introduction of a proper cleaning step is not required. Obviously, reproducibility is a key, mandatory requirement when using similar devices in this frame, since effective comparison with standards or between two or more samples is necessary. The reproducibility of the responses obtained at EGO/SPEs requires reproducibility of the modification of the electrode surface, which was achieved by a suitable stabilisation procedure of the EGO coating, to performed after deposition of the electrode coating. We could observe that quite reproducible responses $(\mathrm{RSD}=$ $12 \%$ ) can be obtained by conditioning a newly realised EGO/SPE with five CV cycles and three DPV cycles in 0.1 M PBS.

The calibration plot finally obtained by combining the results from three EGO/SPEs is reported in the inset of Figure 2. The calculated sensor sensitivity, i.e. the slope of the calibration plot, resulted $2.61( \pm 0.09) \mathrm{nA} / \mathrm{ppb}$, that is a value higher with respect to that found for different amperometric sensors reported so far by the literature (see Table 1). In this respect, it has to be underlined that higher sensitivity values were only found for modified electrodes exploiting adsorptive stripping as the detection technique $[29,33]$. However, this technique requires quite a long pre-concentration step under well-controlled stirring of the solution, which constitutes a condition that is not easy to adopt in portable and rapid sensor systems.

The good reproducibility degree of the responses obtained by following the procedure previously described was also confirmed by comparison of the calibration plots computed by three different EGO modified electrodes $(\mathrm{RSD}=5.0 \%)$. t-Student test applied to the slope of the three calibration plots, considering two of them at a time, demonstrates that the sensitivity of the three similar EGO/SPEs is not significantly different, at a confidence level of $95 \%$.

Measurements at different morphine concentration have been repeated at bare SPEs. In this case, the very much lower intensity of the currents forces to only analyse solutions at significantly higher concentrations, actually preventing the use of such an electrode for reliable morphine quantification. The sensitivity of bare SPEs for morphine detection finally results equal to $0.031( \pm 0.001) \mathrm{nA} / \mathrm{ppb}$, that is a value significantly lower with respect to that defined for EGO modified SPEs. Since measurements previously reported [23] allow us to discard the hypothesis of meaningful differences in the electroactive area of the two devices, this result can be only ascribed to the activation of electrocatalytic processes and to the arising of peculiar diffusion processes at the EGO nanostructured surface [44]. On the other hand, different chemical interactions arising between the 
analyte and either graphite or graphene surfaces can be also invoked in order to explain the better performance of EGO with respect to bare surface.

The performance of EGO/SPEs for morphine detection was also investigated in order to determinate the Limit of Detection (LOD). As suggested by IUPAC [45] and according to a criterion adopted in many papers, the lowest signal value detectable is equal to three times the standard deviation of the background signal. This value, converted to the relevant concentration by exploiting the calibration plot, leads us to calculate a value of $2.5 \mathrm{ppb}$. This value once more demonstrates the good performance of EGO/SPE with respect to similar devices reported in the literature (see Table 1).

On the other hand, a more reliable definition of LOD requires the use of the intercept value of the calibration plot and of the relevant standard deviation [43], allowing not to force the noise affecting the actual signal to coincide with that in the absence of signal. A LOD of $12.7 \mathrm{ppb}$ was computed by following this approach, as the mean value calculated from the three calibration plots obtained at different EGO/SPEs.

As a conclusion of tests in standard water solutions, we can observe that the performance of EGO/SPE is significantly better than many similar sensor systems reported in the literature (Table 1). This result let us envision the possible use of such a sensor in a number of applications. In particular, the very low LOD found, well below that of the cut-off limit adopted for screening tests of morphine in urine samples [10,11], supports the idea of a possible application of the sensor in fast screening tests for the detection of drug abuse.

\subsection{Morphine detection in urine samples}

In order to evaluate the possible application of the sensor for morphine detection in urine samples at concentration levels as low as the cut-off limits, i.e. $300 \mathrm{ppb}$, first tests have been carried out in a well defined and controlled analytical matrix, namely in a synthetic solution mimicking urine. Although literature works generally employ inorganic, electrochemically inert salts to fit the ionic strength of urine samples, we choose a more complex composition, also containing organic species that are actually present in urine, namely urea, creatinine and uric acid. The final $\mathrm{pH}$ of this solution is $6.6( \pm 0.1)$, which is quite close to the value of the physiological matrix.

$\mathrm{NaCl}, \mathrm{Na}_{2} \mathrm{HPO}_{4}, \mathrm{KH}_{2} \mathrm{PO}_{4}, \mathrm{NH}_{4} \mathrm{Cl}$ and $\mathrm{Na}_{2} \mathrm{SO}_{4}$ electrochemically inert salts have been used to obtain a basic composition for synthetic urine, to which subsequently add the different organic species. In this way, we could observe that both creatinine and urea are not electroactive in the potential window of interest for morphine oxidation, whereas uric acid leads to an evident peak at $c a .+0.25 \mathrm{~V}$, at EGO/SPE. Although uric acid is present in urine at a relatively high concentration 
with respect to morphine, as in the case reported in Figure 3, the oxidation of these two species occurs in correspondence to two well separated peaks. In this frame, it should be noticed that the five to one dilution factor has been chosen as a compromise between the possibility to retain quite a good precision in detecting low morphine concentrations and the minimisation of interference effects due to different species present in urine, and particularly of uric acid.

Based on the curves recorded in the same solutions at a bare electrode, it can be inferred that the detection of morphine in this medium is only possible thanks to the activation of electrocatalytic processes by EGO films.

Although a proper definition of a calibration plot in urine samples is not the goal of the use of this sensor system, essentially devoted to the development of a "first alarm" sensor system for drug abuse, voltammetric traces recorded with the same EGO/SPE at different concentrations of morphine (300, 600 and $900 \mathrm{ppb}$ ) show a linear dependence of the oxidation peak current of morphine, indicating the reliability of this sensor response.

Furthermore, the possible occurrence of false positive responses was also tested by considering the most common pharmaceutical compounds possessing anti-inflammatory and analgesic action (paracetamol, acetylsalicylic acid, ibuprofene, ketoprofene, nimesulide), inhibiting stomach acid (lansoprazole) and a common benzodiazepine derivative used for treating many disorders, namely lorazepam. As also suggested by the literature [46-52], only paracetamol resulted electroactive in the potential window used for morphine determination, but gives rise to an oxidation peak at different potential, suggesting that false positive results are not obtained from subjects under paracetamol administration.

Thanks to the quite promising results obtained from EGO/SPE in synthetic urine samples, further tests have been carried out in real samples. Urine has quite a complex chemical composition so that, as expected, by passing from synthetic to real samples the electrochemical signal is affected by further interfering species. They constitute minor components of the matrix, but assume importance when the signal due to the analyte is extremely low. Particular attention should be directed to proteins, to hormones, and to a wide number of metabolites, urobilin included. Due to the presence of these components, several sample treatments are proposed by the literature [29,33,35,53], mainly based on centrifugation steps. However, this approach requires that the analysis is performed in a chemical laboratory. In outlining the procedure to adopt we kept in mind that facile pre-treatment of the sample should be adopted in portable detection systems. As already pointed out, at variance with reported procedures [29,34], a low dilution factor is required in order to satisfy the goal of the paper, i.e. the detection of morphine in urine sample at very low concentration level, namely those defined by cut-off limits in European Countries. 
Best results have been obtained by adding, at first, a suitable amount of concentrated $\mathrm{HCl}$ solution, to induce protein precipitation and protonation of other organic species containing carboxylic moieties. The sample was then filtered in a $0.2 \mu \mathrm{m}$ syringe filter and diluted with $0.1 \mathrm{M}$ PBS, to a final dilution factor of five. The final $\mathrm{pH}$ of the solution depends on $\mathrm{pH}$ of the original sample.

Figure 4 accounts for different DPV curves recorded on urine samples. A first curve reports a DPV response of urine that was simply diluted with PBS solution: the response of uric acid is detectable (peak at $c a .+0.25 \mathrm{~V}$ ), together with a potentially interfering, low signal at more positive potentials. The described pre-treatment of the sample allows the elimination of the species responsible for this last signal, so that uric acid is the only electroactive molecule present in the sample at a significative concentration. Quite interestingly, analyses of urine samples containing $200 \mathrm{ppb}$ morphine, when submitted to the pre-treatment described, let us to record well evident voltammetric signals due to morphine oxidation, clearly distinguishable from that of uric acid and from the background (Figure 4, dotted line).

\section{Conclusions}

We demonstrate here that EGO-modified SPE constitutes a high performance amperometric sensor for morphine quantification, characterised by very higher sensitivity (2.61 nA $\mathrm{ppb}^{-1}$ ) and lower detection limit (2.5 ppb) with respect to similar devices proposed so far by the literature. The high performance is due to the arising of effective electrocatalytic processes in charge of morphine oxidation induced by the presence of a well conductive graphene oxide coating. Furthermore the high reproducibility observed allows the possible use of the sensor system as a disposable device, even though the good repeatability found in standard solutions induces not to discard the possible application of the electrode system in subsequent voltammetric tests after performing the cleaning procedure developed.

Thanks to the performance observed, the device is suitable to be used for morphine screening tests in urine samples even when considering concentration values even lower than the cut-off values defined by American and European regulations. The development of such a portable and disposable sensor system allows us to propose the device for systematic controls of drug abuses, for instance by drivers on the streets or by men at work. 


\section{Acknowledgements}

The research leading to this work was supported by the European Union's Horizon 2020 research and innovation programme (grant agreement n ${ }^{\circ} 696656$ Graphene Flagship) and the EC Marie-Curie ITN- iSwitch (GA no. 642196). 


\section{References}

[1] International Narcotics Control Board. https://www.incb.org/documents/Publications/ AnnualReports/AR2016/English/AR2016_E_ebook.pdf, 2016 (accessed 4 May 2018)

[2] G.D.Busse, D.J.Triggle, Morphine, Chelsea House Publishers, New York, 2006.

[3] S.B. Karch, Drug abuse handbook, $2^{\text {nd }}$ ed.; CRC Press book, Boca Raton, 2006.

[4] J. M. P. J.Garrido, C. Delerue-Matos, F. Borges, T. R. A. Macedo, A. M. Oliveira-Brett, Electrochemical analysis of opiates - an overview, Anal. Lett. 37 (2004) 831 - 844.

[5] E. J. Cone, W. D. Darwin, Rapid assay of cocaine, opiates and metabolites by gas chromatography-mass spectrometry, J. Chromatogr. 580 (1992) 43 - 61.

[6] R. Wasels, F. Belleville, Gas chromatographic-mass spectrometric procedures used for the identification and determination of morphine, codeine and 6-monoacetylmorphine, J. Chromatogr. A 674 (1994) 225 - 234.

[7] M.Y.Salem, S.A.Ross, T.P.Murphy, M.A. El Sohly, GC-MS Determination of Heroin Metabolites in Meconium: Evaluation of Four Solid-Phase Extraction Cartridges, J. Anal. Toxicol. 25 (2001) $93-98$.

[8] M. R. Moeller, S. Steinmeyer, T. Kraemer, Determination of drugs of abuse in blood, J. Chromatogr. B, 713 (1998) 91 - 109.

[9] R. Dams, T.Benijts, W. E. Lambert, A,. P. De Leenheer, J. Chromatogr. B 773 (2002) 53 61.

[10] European Workplace Drug Testing Society. European Guidelines for Workplace Drug Testing in Urine. 2015-11-01 Version 2.0. http://www.ewdts.org/ewdts-guidelines.html, 2015 (accessed 4 May 2018).

[11] Department of health and human services. Mandatory guidelines for federal workplace drug testing programs. Federal register, 82, 7920 - 7970. https://www.gpo.gov/fdsys/pkg/FR-201701-23/pdf/2017-00979.pdf, 2017.

[12] J.M.P.J.Garrido, C.Delerue-Matos, F.Borges, T.R.A.Macedo, A.M. Oliveira-Brett, Electroanalysis 16 (2004) 1419 - 1426.

[13] P. H. Jordan, J. P. Hart, Voltammetric behaviour of morphine at a glassy carbon electrode and its determination in human serum by liquid chromatography with electrochemical detection under basic conditions, Analyst 116 (1991) 991 - 996.

[14] B. Proksa, L. Molnár, Voltammetric determination of morphine on stationary platinum and graphite electrodes, Anal. Chim. Acta 97 (1978), 149 - 154.

[15] A. Navaee, A.Salimi, H.Teymourian, Graphene nanosheets modified glassy carbon electrode for simultaneous detection of heroine, morphine and noscapine, Biosens. Bioel. 31 (2012) 
$205-211$.

[16] A. Niazi, J. Ghasemi, M. Zendehdel, Simultaneous voltammetric determination of morphine and noscapine by adsorptive differential pulse stripping method and least-squares support vector machines, Talanta 74 (2007) $247-254$.

[17] M. H. Pournaghi-Azar, A.Saadatirad, Simultaneous voltammetric and amperometric determination of morphine and codeine using a chemically modified-palladizedaluminum electrode, J. Electroanal. Chem, 624 (2008) 293 - 298.

[18] A. Salimi, R.Hallaj, G. R.Khayatian, Amperometric detection of morphine at preheated glassy carbon electrode modified with multiwall carbon nanotubes, Electroanalysis 17 (2005) 873 879.

[19] R. Seeber, F. Terzi, C.Zanardi, Functional materials in amperometric sensing: polymeric, inorganic, and nanocomposite materials for modified electrodes (Ed. F. Scholz), SpringerVerlag, Heidelberg, 2014.

[20] R. Seeber, L.Pigani, F. Terzi, C. Zanardi, Amperometric sensing. A melting pot for material, electrochemical, and analytical sciences, Electrochim. Acta 179 (2015) 350 - 363.

[21] L. Pigani, M. Musiani, C. Pirvu, F. Terzi, C. Zanardi, R. Seeber, Electro-oxidation of chlorophenols on poly(3,4-ethylenedioxythiophene)-poly(styrene sulphonate) composite electrode, Electrochim. Acta 52 (2007) 1910 - 1918.

[22] M. A. Heras, S. Lupu, L. Pigani, C. Pirvu, R. Seeber, F. Terzi, C. Zanardi, A poly(3,4ethylenedioxythiophene)-poly(styrene sulphonate) composite electrode coating in the electrooxidation of phenol, Electrochim. Acta 50 (2005) 1685 - 1691.

[23] G. Maccaferri, C. Zanardi, Z. Y. Xia, A. Kovtun, A. Liscio, F. Terzi, V. Palermo, R. Seeber, Systematic study of the correlation between surface chemistry, conductivity and electrocatalytic properties of graphene oxide nanosheets, Carbon 120 (2017) 165 - 175.

[24] K. C. Ho, C. Y. Chen, H. C. Hsu, L. C. Chen, S. C. Shiesh, X. Z. Lin, Amperometric detection of morphine at a Prussian blue-modified indium tin oxide electrode, Biosens. Bioel. 20 (2004) $3-8$.

[25] W. M. Yeh, K. C. Ho, Amperometric morphine sensing using a molecularly imprinted polymer-modified electrode, Anal. Chim. Acta 542 (2005) 76 - 82.

[26] K. C. Ho, W. M.Yeh, T. S. Tung, J. Y. Liao, Amperometric detection of morphine based on poly(3,4-ethylenedioxythiophene) immobilized molecularly imprinted polymer particles prepared by precipitation polymerization, Anal. Chim. Acta 542 (2005) 90 - 96.

[27] Y. Zhao, Y. Wu, Y. Zhang, Z. Chen, X. Cao, J. Di, J. Yang, Electrocatalytic behavior and amperometric detection of morphine on ITO electrode modified with directly electrodeposited 
gold nanoparticles, Electroanalysis 21 (2009) 939 - 943.

[28] F. Li, J. Song, D. Gao, Q. Zhang, D. Han, L. Niu, Simple and rapid voltammetric determination of morphine at electrochemically pretreated glassy carbon electrodes, Talanta, 79 (2009) $845-850$.

[29] F. Li, J. Song, C. Shan, D. Gao, X. Xu, L. Niu, Electrochemical determination of morphine at ordered mesoporous carbon modified glassy carbon electrode, Biosens. Bioel. 25 (2010) 1408 $-1413$.

[30] E. Afsharmanesh, H. Karimi-Maleh, A. Pahlavan, J. Vahedi, Electrochemical behavior of morphine at $\mathrm{ZnO} / \mathrm{CNT}$ nanocomposite room temperature ionic liquid modified carbon paste electrode and its determination in real samples, J. Molecular Liquids 181 (2013) 8 - 13.

[31] A. L. Sanati, H. Karimi-Maleh, A. Badiei, P.Biparva, A. A. Ensafi, A voltammetric sensor based on $\mathrm{NiO} / \mathrm{CNT}$ s ionic liquid carbon paste electrode for determination of morphine in the presence of diclofenac, Mater. Sci. Eng. C 35 (2014) 379 - 385.

[32] Y. Li, L. Zou, Y. Li, K. Li, B. Ye, A new voltammetric sensor for morphine detection based on electrochemically reduced MWNTs-doped graphene oxide composite film, Sens. Act. B, $201(2014) 511-519$

[33] A. A. Ensafi, M. M. Abarghoui, B. Rezaei, Simultaneous determination of morphine and codeine using Pt nanoparticles supported on porous silicon flour modified ionic liquid carbon paste electrode, Sens. Act. B219 (2015) 1 - 9.

[34] N. F. Atta, A. Galal, F. M. Abdel-Gawad, E. F. Mohamed, Electrochemical morphine sensor based on gold nanoparticles metalphthalocyanine modified carbon paste electrode, Electroanalysis 27 (2015) 415 - 428.

[35] M. Taeia, F. Hasanpoura, V. Hajhashemi, M. Movahedi, H. Baghlani, Simultaneous detection of morphine and codeine in urine samples of heroin addicts using multi-walled carbon nanotubes modified $\mathrm{SnO}_{2}-\mathrm{Zn}_{2} \mathrm{SnO}_{4}$ nanocomposites paste electrode, App. Surf. Sci, 363 (2016) $490-498$

[36] F. Basiri, M. Taei, Application of spinel-structured $\mathrm{MgFe}_{2} \mathrm{O}_{4}$ nanoparticlesfor simultaneous electrochemical determination diclofenacand morphine, Microchim.Acta 184 (2017) 155 162

[37] Z. Y. Xia, G. Giambastiani, C. Christodoulou, M. V. Nardi, N. Koch, E. Treossi, V. Bellani, S. Pezzini, F. Corticelli, V. Morandi, A. Zanelli, V. Palermo, Synergic exfoliation of graphene with organic molecules and inorganic ions for the electrochemical production of flexible electrodes, ChemPlusChem, 79 (2014) 439 - 446.

[38] S. Park, R. S. Ruoff, Chemical methods for the production of graphenes, Nat. Nanotechnol. 4 
(2009), 217-224.

[39] H. Matsuda, Y.Z. Ayabe, Zurtheorie der Randles-Sevčikschenkathodenstrahl-polarographie, Elektrochem. 59 (1955) 494 - 503.

[40] R. S. Nicholson, I. Shain, Theory of stationary electrode polarography. single scan and cyclic methods applied to reversible, irreversible, and kinetic systems, Anal. Chem. 36 (1964) 706 723.

[41] R.S. Nicholson, Theory and application of cyclic voltammetry for measurement of electrode reaction kinetics, Anal. Chem. 37 (1965) 1351 - 1355.

[42] D. L. Massart, B. G. M. Vandeginste, S. N. Deming, Y. Michotte, L. Kaufman, Chemometrics: a textbook. Book series: Data handling in science and technology, B. G. M.Vandeginste, L. Kaufman (Eds.), vol. 2. Elsevier, Amsterdam. 1988.

[43] W. Funk, V. Dammann, G. Donnevert, Quality assurance in analytical chemistry, VCH, Weinheim, 1995.

[44] K. R. Ward, M. Gara, N. S. Lawrence, R. S. Hartshorne, R. G. Compton, Nanoparticle modified electrodes can show an apparent increase in electrode kinetics due solely to altered surface geometry: the effective electrochemical rate constant for non-flat and non-uniform electrode surfaces, J. Electroanal. Chem. 695 (2013) 1 - 9.

[45] A. D. McNaught, A. Wilkinson, IUPAC. Compendium of Chemical Terminology, 2nd ed. (the "Gold Book"). Blackwell Scientific Publications, Oxford. On-line corrected version: http://goldbook.iupac.org, 1997 (accessed 4 May 2018).

[46] S. Kruanetr, P. Pollard, C. Fernandez, R. Prabhu, Electrochemical oxidation of acetyl salicylic acid and its voltammetric sensing in real samples at a sensitive edge plane pyrolytic graphite electrode modified with graphene Int. J. Electrochem. Sci. 9 (2014) 5699-5711.

[47] A. B. Lima, E. O. Faria, R. H. O. Montes, R. R. Cuhna, E. M. Richter, R. A. A. Munoz, W. T. P. dos Santos, Electrochemical oxidation of ibuprofen and its voltammetric determination at a boron-doped diamond electrode, Electroanalysis 25 (2013) 1585-1588.

[48] L. Švorca, I. Strežováa, K. Kianičkováa, D. M. Stanković, P. Otř́ísald, A. Samphao, An advanced approach for electrochemical sensing of ibuprofen in pharmaceuticals and human urine samples using a bare boron-doped diamond electrode J. Electroanal. Chem. 822 (2018) $144-152$.

[49] M. Murugananthan, S.S. Latha, G. Bhaskar Raju, S. Yoshihara, Anodic oxidation of ketoprofen. An anti-inflammatory drug using boron doped diamond and platinum electrodes, J. Hazard. Mater. 2010, 180, 753-758

[50] S. D. Bukkitgar, N. P. Shetti, R. M. Kulkarni, S. B. Halbhavi, M. Wasim, M. Mylar, P. S. 
Durgi, S. S. Chirmure, Electrochemical oxidation of nimesulide in aqueous acid solutions based on TiO2 nanostructure modified electrode as a sensor, J. Electroanal. Chem. 778 (2016) 103-109.

[51] A. Radi, Anodic voltammetric assay of lansoprazole and omeprazole on a carbon paste electrode, J. Pharm. Biomed. Anal. 2003, 31 1007-1012.

[52] W. F. Smyth, A. Ivaska, A study of the electrochemical oxidation of some 1,4benzodiazepines, Analyst, 1985, 110, 1377-1379.

[53] H. Bagheri, H. Khoshsafar, A. Afkhami, S. Amidi, Sensitive and simple simultaneous determination of morphine and codeine using a $\mathrm{Zn}_{2} \mathrm{SnO}_{4}$ nanoparticle/graphene composite modified electrochemical sensor, New J. Chem. 40 (2016) 7102 - 7112. 


\section{Captions to Figures}

Figure 1. Representative CV curves recorded at bare (blue lines) and EGO modified (black lines) SPEs in 0.1 M PBS ( $\mathrm{pH}=7.0$ ) in absence (dotted lines) and in presence (solid lines) of $46 \mathrm{ppm}$ $(0.16 \mathrm{mM})$ morphine; $0.05 \mathrm{Vs}^{-1}$ potential scan rate.

Figure 2. DPV responses of EGO/SPE registered in $0.1 \mathrm{M} \mathrm{PBS}$, in presence of morphine, subtracted by the background. Inset reports the relevant calibration plot obtained by randomizing the concentration of the morphine solutions under analysis and considering responses deriving from three different devices.

Figure 3. DPV responses on synthetic urine containing $300 \mathrm{ppb}$ morphine at unmodified (red line) and EGO modified (blue solid line) SPEs. As a comparison, the analysis of $300 \mathrm{ppb}$ morphine in absence of uric acid is also reported in the case of EGO/SPE (blue dashed line). In all cases, the original samples were diluted five times with PBS, so that the signal finally recorded is referred to a solution containing $60 \mathrm{ppb}$ morphine and $0.70 \mathrm{gL}^{-1}$ uric acid.

Figure 4. DPV analyses performed with EGO/SPE in urine sample diluted five times with PBS before (blue line) and after (black solid line) additional pre-treatment. Black dashed line reports the signal recorded for an urine sample containing $200 \mathrm{ppb}$ morphine, after acid pre-treatment and dilution as described in the experimental. 


\section{Caption to Tables}

Table 1 - Analytical performance of electrochemical sensors for morphine detection reported by the literature (different sensors are listed from the oldest to that reported in this paper). 


\begin{tabular}{|c|c|c|c|c|c|c|}
\hline \multirow[t]{2}{*}{ electrode surface } & \multirow{2}{*}{$\begin{array}{l}\text { solvent } \\
\text { media }\end{array}$} & \multirow{2}{*}{$\begin{array}{l}\text { electrochemical } \\
\text { technique }\end{array}$} & \multicolumn{2}{|c|}{ sensitivity } & \multirow{2}{*}{$\begin{array}{c}\text { LOD }^{*} \\
\text { ppb }\end{array}$} & \multirow[t]{2}{*}{ ref } \\
\hline & & & $\mathbf{n A} \mathbf{p p b}^{-1}$ & nA ppb ${ }^{-1} m^{-2}$ & & \\
\hline Prussian Blue film & $\mathrm{KCl}$ & amperometry & 0.0589 & $5.89 \times 10^{-4}$ & $2.85 \times 10^{4}$ & 24 \\
\hline PEDOT based MIP & $\mathrm{KCl}$ & amperometry & 0.322 & $3.22 \times 10^{-3}$ & $5.71 \times 10^{4}$ & 25 \\
\hline $\begin{array}{l}\text { MIP fixed in a } \\
\text { PEDOT film }\end{array}$ & $\mathrm{KCl}$ & amperometry & 0.0730 & $1.46 \times 10^{-3}$ & $8.53 \times 10^{4}$ & 26 \\
\hline $\begin{array}{c}\text { multiwalled carbon } \\
\text { nanotubes }\end{array}$ & PBS pH 7 & amperometry & 0.035 & 0.011 & 57 & 18 \\
\hline hanging $\mathrm{Hg}$ drop & $\begin{array}{c}\text { Britton- } \\
\text { Robinson } \\
\text { buffer (pH } \\
10)\end{array}$ & $\begin{array}{c}\text { adsorptive striping } \\
\text { voltammetry with } \\
\text { differential pulse } \\
\text { detection }\end{array}$ & 0.372 & & 3.0 & 16 \\
\hline Prussian Blue film & $\begin{array}{c}\mathrm{KNO}_{3}+ \\
\text { acetate ions } \\
(\mathrm{pH} \mathrm{6})\end{array}$ & amperometry & 0.273 & 0.0385 & 228 & 17 \\
\hline gold nanoparticles & PBS pH 7.0 & cyclic voltammetry & 1.19 & 0.033 & 60 & 27 \\
\hline activated GC & PBS pH 7.4 & $\begin{array}{c}\text { adsorptive striping } \\
\text { voltammetry with } \\
\text { linear sweep } \\
\text { detection }\end{array}$ & 0.251 & 0.0355 & 57 & 28 \\
\hline $\begin{array}{l}\text { ordered mesoporous } \\
\text { carbon film }\end{array}$ & PBS pH 7.0 & $\begin{array}{c}\text { adsorptive striping } \\
\text { voltammetry with } \\
\text { linear sweep } \\
\text { detection }\end{array}$ & 6.10 & & 14.3 & 29 \\
\hline $\begin{array}{c}\text { Chemically reduced } \\
\text { GO }\end{array}$ & PBS pH 8.0 & $\begin{array}{l}\text { differential pulse } \\
\text { voltammetry }\end{array}$ & 0.077 & 0.025 & 128 & 15 \\
\hline $\begin{array}{c}\mathrm{ZnO}-\text { carbon } \\
\text { nanotubes } \\
\text { composite in carbon } \\
\text { paste } \\
\end{array}$ & PBS pH 8.0 & $\begin{array}{l}\text { square wave } \\
\text { voltammetry }\end{array}$ & 0.0529 & & 17.1 & 30 \\
\hline $\begin{array}{c}\text { hydrophilic } \\
\text { ionic liquid }-\mathrm{NiO}- \\
\text { carbon nanotube } \\
\text { composite }\end{array}$ & PBS pH 7.0 & $\begin{array}{l}\text { square wave } \\
\text { voltammetry }\end{array}$ & 0.176 & & 2.9 & 31 \\
\hline $\begin{array}{l}\text { electrochemically } \\
\text { reduced multiwalled } \\
\text { carbon nanotube } \\
\text { and graphene oxide } \\
\text { composite }\end{array}$ & PBS pH 4.5 & $\begin{array}{l}\text { adsorptive striping } \\
\text { voltammetry with } \\
\text { linear sweep } \\
\text { detection }\end{array}$ & 36.2 & 5.12 & 14 & 32 \\
\hline $\begin{array}{l}\text { Pt nanoparticles } \\
\text { supported on porous } \\
\text { silicon coating }\end{array}$ & $\begin{array}{c}\text { Britton- } \\
\text { Robinson } \\
\text { buffer pH } 6.0\end{array}$ & $\begin{array}{c}\text { adsorptive striping } \\
\text { with differential } \\
\text { pulse voltammetry } \\
\text { detection }\end{array}$ & 0.701 & 0.223 & 8.6 & 33 \\
\hline $\begin{array}{c}\text { Au nanoparticles } \\
\text { and Co } \\
\text { phthalocyanine in } \\
\text { carbon paste }\end{array}$ & $\begin{array}{c}\text { Britton- } \\
\text { Robinson } \\
\text { buffer pH } 7.4\end{array}$ & $\begin{array}{l}\text { differential pulse } \\
\text { voltammetry }\end{array}$ & 0.057 & & 1.6 & 34 \\
\hline $\begin{array}{c}\mathrm{SnO}_{2}-\mathrm{Zn}_{2} \mathrm{SnO}_{4} \text { into } \\
\text { multi-walled carbon } \\
\text { nanotube paste }\end{array}$ & PBS pH 6.0 & $\begin{array}{l}\text { differential pulse } \\
\text { voltammetry }\end{array}$ & 0.610 & & 2.6 & 35 \\
\hline $\begin{array}{l}\mathrm{MgFe} 2 \mathrm{O} 4 / \text { graphite } \\
\text { paste electrode } \\
\text { modified with } \\
\text { multi-walled carbon } \\
\text { nanotubes } \\
\end{array}$ & PBS pH 7.0 & $\begin{array}{l}\text { differential pulse } \\
\text { voltammetry }\end{array}$ & 0.322 & & 2.9 & 36 \\
\hline EGO coating & PBS at $\mathrm{pH} 7$ & $\begin{array}{l}\text { differential pulse } \\
\text { voltammetry }\end{array}$ & 2.61 & 0.21 & 2.5 & this paper \\
\hline
\end{tabular}

* calculated as three times the standard deviation of the blank signal 


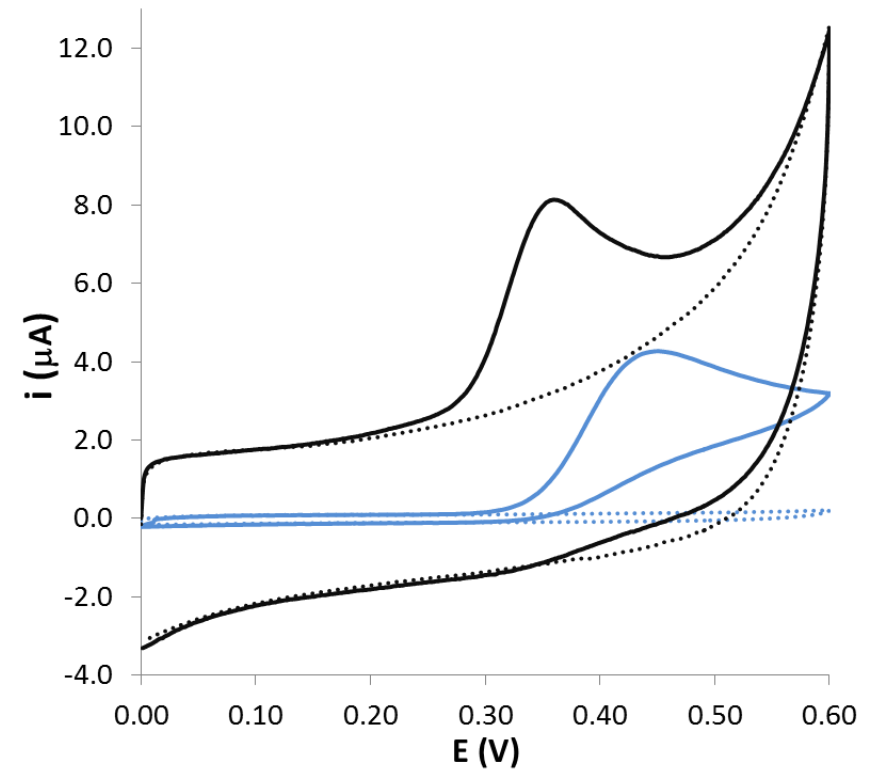

Figure 1 


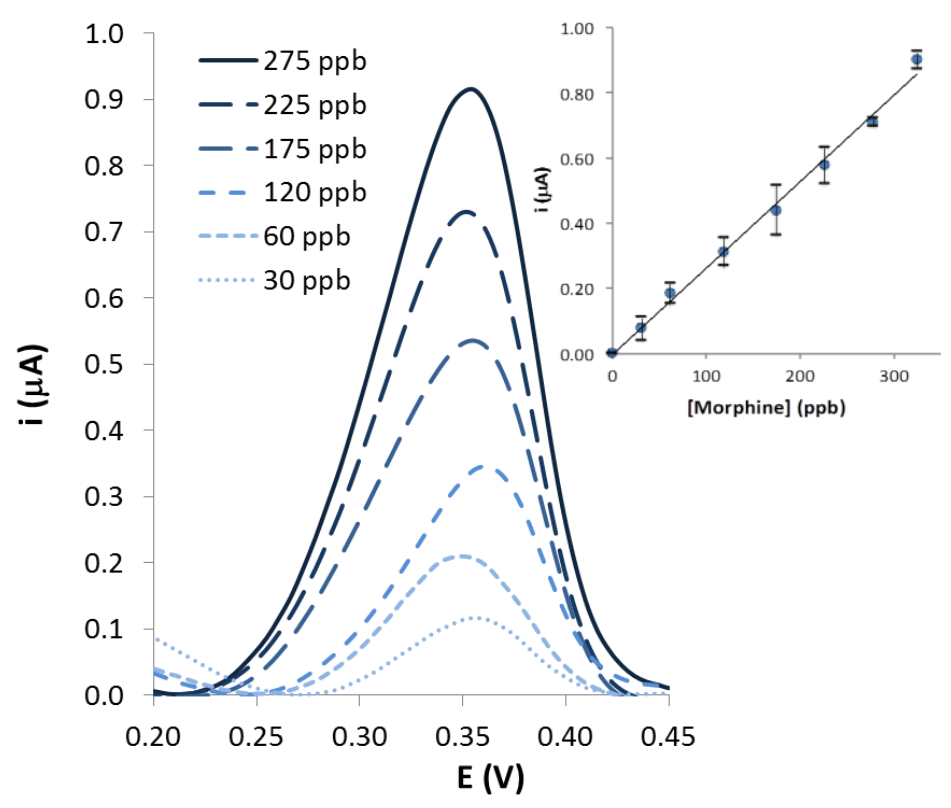

Figure 2 


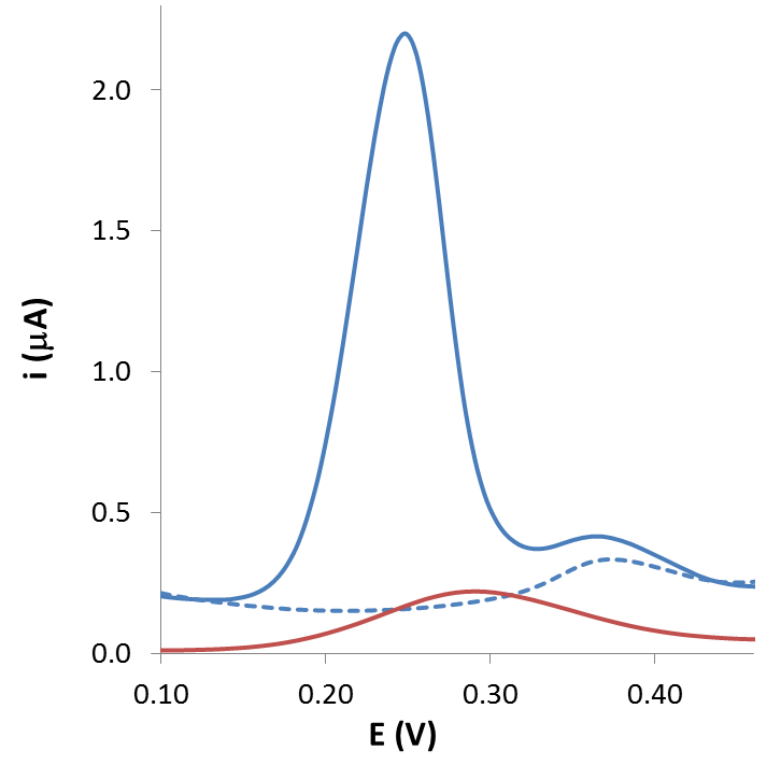

Figure 3 


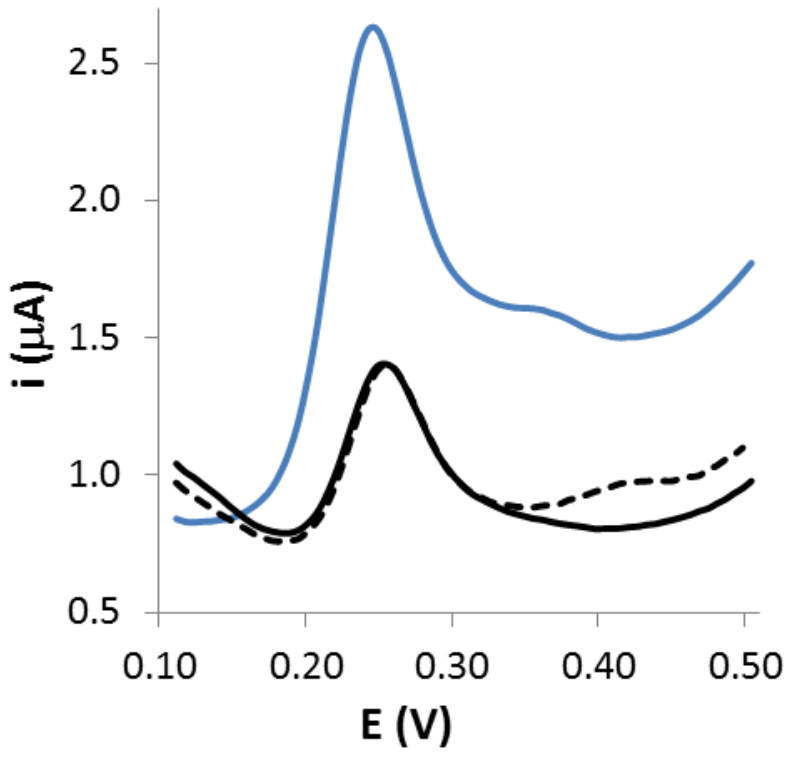

Figure 4 